\title{
Photoprotection in intact cells of photosynthetic bacteria: quenching of bacteriochlorophyll fluorescence by carotenoid triplets
}

\author{
Gábor Sipka $^{1,2} \cdot$ Péter Maróti $^{1}$
}

Received: 23 May 2017 / Accepted: 16 August 2017 / Published online: 24 October 2017

(C) Springer Science+Business Media B.V. 2017

\begin{abstract}
Upon high light excitation in photosynthetic bacteria, various triplet states of pigments can accumulate leading to harmful effects. Here, the generation and lifetime of flash-induced carotenoid triplets $\left({ }^{3} \mathrm{Car}\right)$ have been studied by observation of the quenching of bacteriochlorophyll (BChl) fluorescence in different strains of photosynthetic bacteria including $R v x$. gelatinosus (anaerobic and semianaerobic), Rsp. rubrum, Thio. roseopersicina, Rba. sphaeroides 2.4.1 and carotenoid- and cytochrome-deficient mutants $R b a$. sphaeroides $\mathrm{Ga}, \mathrm{R}-26$, and $c y c A$, respectively. The following results were obtained: (1) ${ }^{3} \mathrm{Car}$ quenching is observed during and not exclusively after the photochemical rise of the fluorescence yield of $\mathrm{BChl}$ indicating that the charge separation in the reaction center (RC) and the carotenoid triplet formation are not consecutive but parallel processes. (2) The photoprotective function of ${ }^{3} \mathrm{Car}$ is not limited to the RC only and can be described by a model in which the carotenoids are distributed in the lake of the BChl pigments. (3) The observed lifetime of ${ }^{3} \mathrm{Car}$ in intact cells is the weighted average of the lifetimes of the carotenoids with various numbers of conjugated double bonds in the bacterial strain. (4) The lifetime of ${ }^{3} \mathrm{Car}$ measured in the light is significantly shorter $(1-2 \mu \mathrm{s})$ than that measured in the dark $(2-10 \mu \mathrm{s})$. The difference reveals the importance of the dynamics of ${ }^{3} \mathrm{Car}$ before relaxation. The results will be discussed not only in terms of energy levels of the ${ }^{3} \mathrm{Car}$ but also in terms of
\end{abstract}

Péter Maróti

pmaroti@sol.cc.u-szeged.hu

1 Department of Medical Physics, University of Szeged, Rerrich Béla tér 1, Szeged 6720, Hungary

2 Institute of Plant Biology, Biological Research Center, Hungarian Academy of Sciences, Szeged 6726, Hungary the kinetics of transitions among different sublevels in the excited triplet state of the carotenoid.

Keywords Bacterial photosynthesis - Intact cells . Fluorescence induction · Triplet quenching · Lake model

\section{Introduction}

Closely coupled bacteriochlorophylls (BChls) and carotenoids (Car) organized in rings are the major pigments of the light-harvesting systems (LH1 and LH2) of photosynthetic bacteria (Fig. 1). This assures efficient capture of light energy and rapid energy transfer from LH2 to LH1 and then to the reaction center (RC) (Hess et al. 1995). Each lightharvesting complex is known to consist of oligomeric pairs of transmembrane proteins, termed $\alpha$ and $\beta$, to which BChls $(a$ and $b$ ) and accessory Car pigments are non-covalently attached (Hawthornthwaite and Cogdell 1991).

In LH1, 24-32 BChls and 12-16 carotenoids are arranged in a ring or ring fragment surrounding the $\mathrm{RC}$ (Koepke et al. 1996; Papiz et al. 2003). The BChl-to-Car ratio in LH1 complexes typically varies between 2:1 in Rhodospirillum (Rsp.) rubrum and 1:1 in Rhodobacter (Rba.) sphaeroides (Hunter et al. 1988; Cogdell 1986). The BChl-to-Car ratio in LH2 was estimated to be 3:1 in Rubrivivax (Rvx.) gelatinosus (Ranck et al. 2001) and in Rba. sphaeroides (Cogdell 1978).

In addition to serving as accessory light-harvesting pigments (Cogdell and Frank 1987), carotenoids may play a structural role (Lang and Hunter 1994; Fraser et al. 2001; Formaggio et al. 2001), and provide protection against photooxidative damage (Griffiths et al. 1955; Cogdell et al. 2000, 2004; Glaeser and Klug 2005). The light energy absorbed by the carotenoids in the blue-green region of the visible spectrum (where BChls are weak absorbers) 


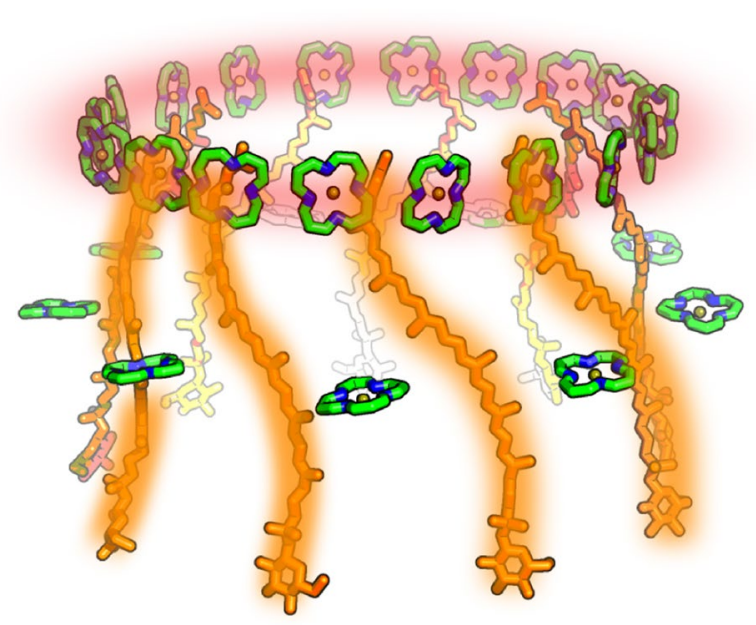

Fig. 1 Illustration of the organization and coupling of the BChl (green) and carotenoid (orange) pigments in the LH2 complex of photosynthetic bacterium (structure from Rps. acidophila, 2FKW). The macrocycles of the $\mathrm{B} 850$ and $\mathrm{B} 800 \mathrm{BChls}$ are arranged to the plane of the membrane perpendicular and parallel, respectively

can be rapidly transferred to the BChls thus increasing the cross-sectional area of the spectrum available for capture by the bacteria. In order to fulfill these functions, carotenoids are bound in close proximity to BChls (Fig. 1). The singlet-singlet energy transfer from carotenoid to $\mathrm{BChl}$ is very efficient: its quantum efficiency is close to $100 \%$ in the B800-850 light-harvesting complex of Rba. sphaeroides (Cogdell et al. 1981; Ueda et al. 1985). The photoprotective function of carotenoids can occur either directly by triplet-triplet energy transfer (Fig. 2) from ${ }^{3} \mathrm{BChl}^{*}$ to the carotenoid

$\mathrm{BChl}+\mathrm{h} v+\mathrm{Car} \rightarrow{ }^{1} \mathrm{BChl} *+\mathrm{Car} \rightarrow{ }^{3} \mathrm{BChl} *+\mathrm{Car} \rightarrow{ }^{1} \mathrm{BChl}+{ }^{3} \mathrm{Car} *$

or indirectly via the formation of singlet oxygen:

${ }^{3} \mathrm{BChl} *+{ }^{3} \mathrm{O}_{2}+\mathrm{Car} \rightarrow{ }^{1} \mathrm{BChl}+{ }^{1} \Delta_{\mathrm{g}} \mathrm{O}_{2}{ }^{*}+\mathrm{Car} \rightarrow{ }^{1} \mathrm{BChl}+{ }^{3} \mathrm{O}_{2}+{ }^{3} \mathrm{Car} *$

By intersystem crossing, the excited singlet BChl, ${ }^{1} \mathrm{BChl}^{*}$ forms triplet ${ }^{3} \mathrm{BChl}$ (Eq. 1a) whose otherwise long-lived state shortens essentially by energy transfer ("quenching") to triplet oxygen ${ }^{3} \mathrm{O}_{2}$ creating excited singlet oxygen ${ }^{1} \mathrm{O}_{2}{ }^{*}$ which is highly damaging to many cell constituents (Eq. 1b).

The carotenoids, however, are able to quench ${ }^{3} \mathrm{BChl} *$ at a much higher rate $\left[(\sim 30 \mathrm{~ns})^{-1}\right]$ than that of ${ }^{3} \mathrm{O}_{2}\left[(\sim 50 \mathrm{~ms})^{-1}\right]$, thus they prevent the formation of the very reactive singlet oxygen and is therefore the predominant reaction. The reaction ${ }^{3} \mathrm{BChl} *+{ }^{1} \mathrm{Car} \rightarrow{ }^{1} \mathrm{BChl}+{ }^{3} \mathrm{Car} *$ is mediated through an electron exchange interaction (the Dexter mechanism). The decay times of ${ }^{3} \mathrm{BChl}^{*}$ associated with

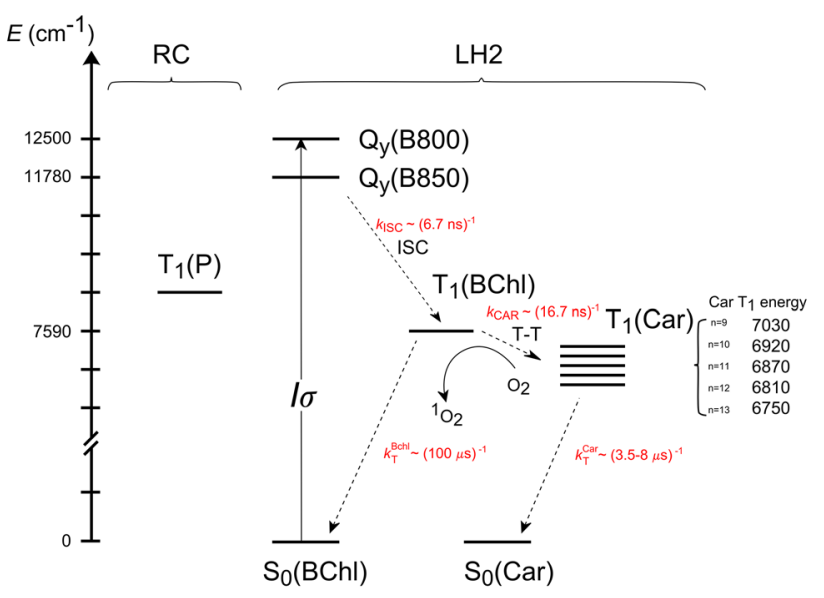

Fig. 2 Triplet energy levels of BChls in $\mathrm{RC}$ [dimer $\left.\mathrm{T}_{1}(\mathrm{P})\right]$ and in $\mathrm{LH} 2\left[\mathrm{~T}_{1}(\mathrm{BChl})\right]$ and of all-trans carotenoids $\left[\mathrm{T}_{1}(\mathrm{Car})\right]$ with numbers of conjugated double bonds $n=9-13$ in LH2. The excited BChl triplets are populated by direct excitation of the singlet energy levels of $\mathrm{BChl}\left[\mathrm{Q}_{\mathrm{y}}(\mathrm{B} 800)\right.$ and $\left.\mathrm{Q}_{\mathrm{y}}(\mathrm{B} 850)\right]$ via intersystem crossing (ISC) and can be depopulated either by triplet-triplet (T-T) energy transfer to the carotenoids (rate constant $k_{\mathrm{CAR}}$ ) or by spontaneous relaxation to the ground state $\mathrm{S}_{0}(\mathrm{BChl})$ with rate constant $k_{\mathrm{T}}{ }^{\mathrm{BChl}}$. The spontaneous decay constant of $\mathrm{T}_{1}(\mathrm{Car})$ is denoted by $k_{\mathrm{T}}{ }^{\mathrm{Car}}$. The $\mathrm{T}_{1}(\mathrm{Car})$ energies of carotenoids in the LH2 complexes with conjugation length $n=9$ (neurosporene), $n=10$ (spheroidene), and $n=11$ (lycopene + rhodopsin) have been determined from Rba. sphaeroides G1C, Rba. sphaeroides 2.4.1, and Rsp. molischianum, respectively (Rondonuwu et al. 2004)

the RC or light-harvesting complex (LHC) are much longer in the absence of Cars (in carotenoidless mutant of Rba. sphaeroides) and can be approximated by 10 and $100 \mu \mathrm{s}$, respectively (Monger et al. 1976; Daviso et al. 2009; Mandal et al. 2017). The carotenoids offer double protection to the bacterium: they not only quench ${ }^{3} \mathrm{BChl}^{*}$ (Eq. 1a) (Borland et al. 1989; Pan et al. 2011) (which prevents the generation of singlet oxygen) but they also scavenge singlet oxygen once established (Eq. 1b) (Foote and Denny 1968). At the end of the processes, the triplet carotenoid is deactivated to singlet carotenoid by heat emission $\left({ }^{3} \mathrm{Car} * \rightarrow{ }^{1} \mathrm{Car}+\right.$ heat $)$ in an oxygen-dependent manner in the time range of several $\mu$ s. Although the protective role of ${ }^{3} \mathrm{Car} *$ is considered wellestablished, the exact rate and mechanism of the ${ }^{3} \mathrm{Car} *{ }^{1} \mathrm{Car}$ relaxation in intact cells is still a matter of debate.

The photoprotective mechanism requires the carotenoid with the lowest energy state [e.g., in LH2 the spheroidene's triplet state ${ }^{3} \mathrm{Car} *, 84.1 \mathrm{~kJ} / \mathrm{mol}=7030 \mathrm{~cm}^{-1}$ (Rondonuwu et al. 2004)] to be lower than the excitation energy of the ${ }^{1} \mathrm{O}_{2} *\left[94 \mathrm{~kJ} / \mathrm{mol}=7858 \mathrm{~cm}^{-1}\right.$ (Bensasson et al. 1976) $]$. Carotenoids with more than seven conjugated double bonds are able to quench ${ }^{3} \mathrm{BChl} *$ and those with nine or more double bonds can quench the singlet oxygen state (Claes and Nakayama 1959; Mathis and Kleo 1973).

The connection between the carotenoid structure and excited-state energy of triplet transfer between the primary 
donor and carotenoids in RC of photosynthetic bacteria has long been revealed (Farhoosh et al. 1997). The carotenoids usually have the 15-cis configuration with some out-of-plane twist along the conjugated backbone in the RC (Hashimoto et al. 2006), and an all-trans configuration either twisted (Rsp. rubrum) or planar (Rba. sphaeroides) in the LHC [Koyama's rule (Koyama 1991)]. The chain twist depends on the protein environment and is not specific to the type of the carotenoid. The natural selection of all-trans and 15-cis carotenoid configurations is supposed to be related to lightharvesting and photoprotective functions of the carotenoids in the LHC and RC, respectively (Koyama et al. 1996, 2007). The strict distinction between light-harvesting and photoprotective functions of carotenoids can be debated as BChl triplets are readily generated not only in the $\mathrm{RC}$ but in the LHC, as well. In addition to this uncertainty, the molecular mechanisms of the photoprotective function of the carotenoid triplets have still not been determined in detail.

Under natural conditions, the excitation energy is efficiently transferred from the antenna to the photochemically active pigment of the RC and trapped by charge separation, with a quantum yield close to unity (Wraight and Clayton 1974). A small fraction of the absorbed light is emitted as $\mathrm{BChl}$ fluorescence which is quenched not only by photochemistry but by interactions with carotenoid triplets via an excited-state annihilation process (singlet-triplet fusion) (Monger and Parson 1977; Breton et al. 1979). Therefore, measurements of time-resolved $\mathrm{BChl}$ fluorescence provide a powerful analytic tool to investigate processes of excited energy transfer, photoprotection, and photochemical trapping in RC (van Grondelle and Duysens 1980; Kocsis et al. 2010; Asztalos et al. 2015; Maróti et al. 2013; Sipka and Maróti 2016). The transfer of triplet energy has so far been understood mainly in general terms and in many cases the identification of the actual pigments and responsible processes is lacking. Furthermore, the details of the dynamic interaction between the triplet-excited carotenoids and/or BChls and their environment are not well understood. With this work, we attempt to fill this gap.

Despite their biological importance as a protection against the oxidation by singlet oxygen, natural Car triplet states are poorly characterized in whole cells and the available information mostly concerns model (or isolated) systems. Here, the kinetics (induction) of BChl fluorescence was tracked upon intense laser diode excitation in different strains of photosynthetic bacteria. The red laser light and the rectangular excitation profile had dual benefits: the Car triplets were generated exclusively via the relatively slow BChl triplet-Car triplet exchange processes and the kinetics of their formation could be followed from the quenching of the $\mathrm{BChl}$ fluorescence directly. These studies provide a systematic approach to explore the effects of the structure and dynamics of carotenoids on their triplet lifetime in intact cells, and direct experimental evidence for a process that is integral to the photoprotective role of carotenoids in photosynthetic bacteria.

\section{Materials and methods}

\section{Bacterial strains, conditions, and carotenoid biosynthesis}

Cells of purple non-sulfur photosynthetic bacterium $R b a$. sphaeroides strain 2.4.1 (Maróti and Wraight 1988), Rsp. rubrum, Rvx. gelatinosus (Vermeglio et al. 2012), and carotenoidless Rba. sphaeroides R-26 were cultivated anaerobically in Siström minimal medium in $1 \mathrm{~L}$ screw top flasks under continuous illumination of about $13 \mathrm{~W} / \mathrm{m}$ provided by tungsten lamps $(40 \mathrm{~W})$ after incubation in the dark for 5-7 $\mathrm{h}$. The cytochrome $c_{2}$-deficient mutant of Rba. sphaeroides cycA I (kindly provided by Prof. Dr. T. Donohue, University of Wisconsin, USA) was cultivated in the dark on a shaker $(1 \mathrm{~Hz})$ in the presence of antibiotic kanamycin and spectinomycin in concentrations of $50 \mu \mathrm{g} / \mathrm{mL}$. The phototrophic purple sulfur bacterium Thiocapsa (Thio.) roseopersicina (obtained from Dr. Cs. Bagyinka, Biological Research Center Hungarian Academy of Sciences, Institute of Biophysics, Hungary) was grown anaerobically in a modified Pfennig's medium (Bagyinka et al. 1981).

As anoxygenic purple bacteria may choose either the spheroidene or the spirilloxanthin pathways or both in carotenogenesis, a large scale of excited-state dynamics and energetics of carotenoids can be studied by the selection of the conjugation length (the number $n=n_{\mathrm{C}=\mathrm{C}}+n_{\mathrm{C}=\mathrm{O}}$ of conjugated double bonds) in the range of $n=9-15$. Rba. sphaeroides possesses the spheroidene pathway and $R s p$. rubrum has the spirilloxanthin pathway, whereas $R v x$. gelatinosus shows up both spheroidene and spirilloxanthin pathways in carotenogenesis. The composition of the Cars depends on the cultivation. For example, Rvx. gelatinosus produces short chain Cars under anaerobic conditions but long chain (mono- and diketo derivatives) Cars under semiaerobic conditions. The bacterial strains and growing conditions used in this study are summarized in Table 1.

\section{Fluorescence measurements and conditions}

The kinetics and yield of the BChl fluorescence generated by a rectangular excitation profile from a high-power laser diode ( $2 \mathrm{~W}$, Roithner LaserTechnik) were recorded by a homebuilt spectrofluorometer (Maróti 2008). The emission wavelength and bandwidth of the laser diodes were $804 \pm 0.5 \mathrm{~nm}$ which assured close to perfect excitation, because of its coincidence with the $800 \mathrm{~nm}$ absorption band of the $\mathrm{LH} 2$ antenna 
Table 1 Bacterial strains used in this study together with carotenoid compositions (Takaichi 1999; Koyama et al. 2007; Chi et al. 2015) and essential quantities [triplet lifetimes, activation energies of
$\mathrm{T}_{1} \rightarrow \mathrm{S}_{0}$ transition, critical light intensities, and efficiency of triplet generation (see Fig. 6b)] determined here

\begin{tabular}{|c|c|c|c|c|c|c|}
\hline \multirow[t]{2}{*}{ Strains } & \multirow[t]{2}{*}{ Carotenoids ${ }^{\text {conjugation chain length }}(\%$ of total) } & \multicolumn{2}{|c|}{$\begin{array}{l}\text { Observed triplet } \\
\text { lifetime }\end{array}$} & \multirow{2}{*}{$\begin{array}{l}\text { Activation } \\
\text { energy } E_{\mathrm{A}}(\mathrm{kJ} / \\
\text { mol) }\end{array}$} & \multirow[t]{2}{*}{$I_{\text {crit }}\left(\mu \mathrm{s}^{-1}\right)$} & \multirow[t]{2}{*}{$\Delta k_{\mathrm{T}} / \Delta I$} \\
\hline & & $\overline{\tau^{\mathrm{dark}}(\mu \mathrm{s})}$ & $\tau^{\text {light }}(\mu \mathrm{s})$ & & & \\
\hline Rba. sphaeroides $\mathrm{Ga}$ & $\begin{array}{l}\text { neurosporene }^{9}(48 \%) \text {; chloroxanthin }{ }^{9}(37 \%) \text {; } \\
\text { 3,4-dihydrospheroidene }{ }^{9}(14 \%)\end{array}$ & $7.24 \pm 0.24$ & $7.3 \pm 0.3$ & 17.69 & 2.1 & 0.02 \\
\hline Rba. sphaeroides 2.4 .1 & spheroidene $^{10}(90 \%)$; spheroidenone ${ }^{11}(10 \%)$ & $5.82 \pm 0.1$ & $2.7 \pm 0.2$ & 2.62 & 1.8 & 0.012 \\
\hline Rba. sphaeroides cycA & $\begin{array}{l}\text { spheroidenone }^{11} \text { and } \mathrm{OH} \text {-spheroidenone }{ }^{11} \\
\quad(100 \%)\end{array}$ & $4.18 \pm 0.27$ & $2.7 \pm 0.35$ & N/A & 1.3 & 0.02 \\
\hline Rvx. gelatinosus (anaerobic) & $\begin{array}{l}\text { spheroidene }^{10}(36 \%) ; \text { OH-spheroidene }{ }^{10}(52 \%) \\
\text { OH-spheroidenone }{ }^{11}(6 \%) \text {; spirilloxanthin }{ }^{13} \\
(6 \%)\end{array}$ & $4.42 \pm 0.14$ & $2.8 \pm 0.3$ & 3.1 & 1.6 & 0.019 \\
\hline Rvx. gelatinosus (semi-aerobic) & $\begin{array}{l}\text { spheroidene }^{10}(1 \%) ; \text { OH-spheroidene }{ }^{10}(3 \%) \\
\text { spheroidenone } \\
\text { (73\%); 2-keto-spirilloxanthin }{ }^{14}(3 \%) ; 2,2^{\prime} \\
\text { diketo-spirilloxanthin }^{15}(10 \%)\end{array}$ & $3.75 \pm 0.35$ & $2.3 \pm 0.5$ & N/A & 1.1 & 0.08 \\
\hline Rsp. rubrum (120 h) & $\begin{array}{l}\text { rhodovibrin }^{12} \text { and anhydrorhodovibrin } \\
\text { spirilloxanthin }\end{array}$ & $4.0 \pm 0.2$ & $3.2 \pm 0.4$ & N/A & 1.7 & 0.19 \\
\hline Thio. roseopersicina & spirilloxanthin $^{13}(100 \%)$ & $3.68 \pm 0.12$ & N/A & N/A & N/A & N/A \\
\hline
\end{tabular}

complex of Rba. sphaeroides. The measurements were carried out with bacterial cell cultures in a $3 \times 3 \mathrm{~mm}$ prismatic quartz cuvette in a temperature-controlled sample holder. The maximum intensity of excitation was 2.1 einstein $/ \mathrm{m}^{2} / \mathrm{s}$ that was attenuated by calibrated neutral density filters. Due to the reciprocity of the intensity of light excitation and the photochemical rise time, the photochemical rate was used as an internal calibration to measure the intensity of light excitation. The excitation induced by a flash of the laser diode had the form of a step function with a rise time $<100 \mathrm{~ns}$. For determination of the yield and kinetics of the BChl fluorescence, a fluorescent dye IR-806 (Sigma) was used as reference. The BChl fluorescence was detected by a large area (diameter $10 \mathrm{~mm}$ ) and high gain $\mathrm{Si}$-avalanche photodiode as detector (APD; model 394-70-72-581; Advanced Photonix, Inc., USA) that was protected from the scattered laser light by an IR cutoff filter (Schott RG-850). The timing of the experiments was controlled by a Digital Delay-Pulse Generator (Berkeley Nucleonics Corporation (BNC) 555) via custom-designed LabVIEW software.

\section{Light-induced absorption change}

The cells were re-suspended in fresh medium, anaerobically adapted in the dark and bubbled with nitrogen for $15 \mathrm{~min}$ prior to measurement. The kinetics of absorption changes of the whole cells induced by laser diode (Roithner LaserTechnik LD808-2-TO3), using a wavelength of $804 \mathrm{~nm}$ and maximum power $2 \mathrm{~W}$, and a rectangular excitation profile of variable duration was detected by a home-constructed spectrophotometer. For the measuring light, a 130-W tungsten lamp was used. A monochromator (Jobin-Yvon H-20 with a concave holographic grating) was used to disperse the measuring light and to protect the detector from the scattered laser light. The monochromatic transmitted measuring light was detected by photomultiplier (R928 Hamamatsu) which was connected to a differential amplifier and to a digital oscilloscope (Tektronix TDS 3032). Samples were placed in a quartz cuvette ( $3 \times 3 \mathrm{~mm}$ cross section). The light-induced energization of the membrane was monitored by electrochromic band shift of the carotenoids at wavelengths between 510 and $600 \mathrm{~nm}$.

\section{Curve fitting procedures}

Least-squares optimization was used (1) to estimate the model parameters in Eqs. (2, 3, 4, and 5) to fit the observed kinetics (Figs. 3a, 7) and (2) to determine triplet decay constants of carotenoids of different conjugation chain lengths from set of linear equations including carotenoid composition and measured triplet lifetimes for different bacterial strains (Fig. 6). The optimization algorithms were implemented in MATLAB (The MathWorks, Natick, MA).

\section{Results}

\section{Triplet (dark and light) lifetimes of the antenna carotenoids}

Upon laser excitation of whole cells of Rba. sphaeroides using a rectangular illumination profile, the fluorescence 
yield of the $\mathrm{BChl}$ produces a particular kinetics (Fig. 3). The yield $\left(F / F_{0}\right)$ is defined as the ratio of the fluorescence level $(F)$ at arbitrary time to the fluorescence level of the open RC that corresponds to the initial fluorescence level $\left(F_{0}\right)$.

In the first microseconds, the fluorescence yield increases to its maximum $\left(F_{\max }\right)$ until the open $\mathrm{RC}$ has completely disappeared (the rising phase); the decreasing phase is the result of the appearance of the triplet quencher: $\mathrm{BChl}$ or carotenoid. The higher is the intensity of the excitation, the faster is the photochemical rise and the more pronounced is the triplet quenching (Fig. 3a). At the highest intensity of excitation used in our experiments, about $50 \%$ of the $\mathrm{BChl}$ variable fluorescence $\left(F_{\max }-F_{0}\right)$ is quenched by the carotenoid triplets. After termination of the excitation in the stationary state, the Car triplets disappear in the dark with a characteristic rate constant $k_{\mathrm{D}}$ that can be determined by a double-flash experiment (Fig. 3b). The first laser flash closes the open RCs (terminates the photochemistry) and produces Car triplets within a few microseconds. This is reflected by an initial increase of the BChl fluorescence (photochemistry) followed by its gradual decrease (due to quenching by Car triplets) to a stationary level determined by the intensity of the excitation. After establishment of the stationary state, the first flash is terminated and the Car triplets will disappear in the dark with characteristic rate constant $k_{\mathrm{D}}$. This can be tested by firing a second flash with the same intensity as the first one. The observed initial fluorescence level at the second flash depends on the dark delay between the two flashes. By tracking the fluorescence levels at the beginning of the second flash as a function of the dark delay (dashed line in Fig. 3b), the data fit to a monoexponential

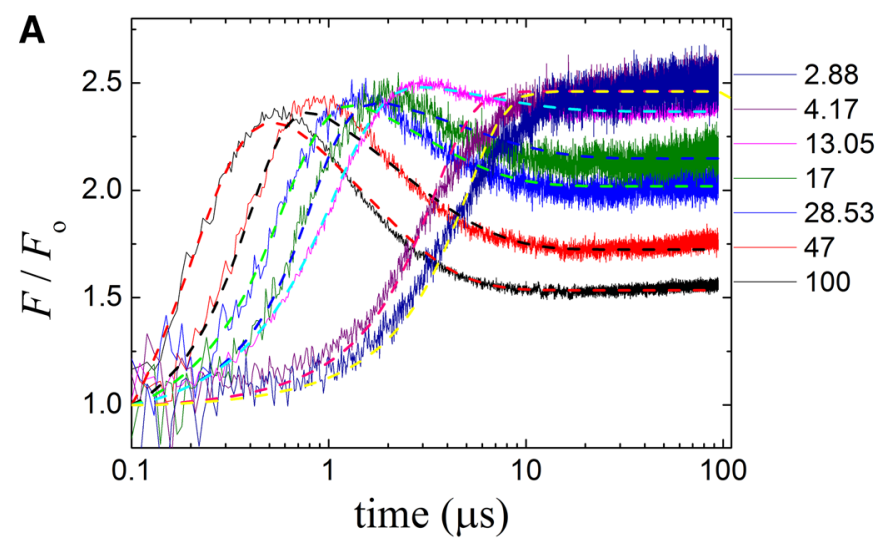

Fig. 3 Kinetics of the yield of BChl fluorescence from whole cells of Rba. sphaeroides under single flash (a) and double-flash (b) excitation. Panel $A$ the fluorescence levels $(F)$ obtained at different laser excitation intensities (see the attenuation in the inset) were referred to the corresponding initial fluorescence levels $F_{0}$. The set of fitted curves (dashed lines) were obtained from exciton migration model described by Eqs. (2, 3, 4, and 5) after use of the numerical values function characterizing the rate constant of deactivation of the triplet state, $k_{\mathrm{D}}$ (Fig. 4a). For different bacterial strains, the $k_{\mathrm{D}}$ values range from $(3.7 \mu \mathrm{s})^{-1}$ to $(7.3 \mu \mathrm{s})^{-1}$ and are tabulated in Table 1 .

As expected, the lifetime of the triplet state is highly sensitive to the oxygen content of the atmosphere: the oxygen accelerates the decay of the Car triplet state by a factor of about 7 (Fig. 4b). The dependence of the observed triplet lifetime on the carotenoid constitution of the bacterial strains obtained from fluorescence quenching experiments can be supported directly by flash-induced absorption change measurements of the carotenoid triplets (Fig. 4c). The fluorescence quenching experiments offer better time resolution of the carotenoid lifetime than those of light-induced absorption measurements.

The rate of the carotenoid triplet production in the light can be characterized by a rate constant $k_{\mathrm{L}}$ that describes the rate of adaptation of the carotenoids to stationary light conditions. This can be measured by a second rectangular flash (Fig. 5a) after a first flash which closes the RC (Fig. 3a). The dark delay between the two flashes should be long enough for the carotenoid triplets to decay but not long enough to re-open the RC (see Fig. 4a). This condition is fulfilled with a $40 \mu$ s dark interval between the flashes and the addition of terbutryn to prevent inter-quinone electron transfer. The $k_{\mathrm{L}}$ values could be obtained by monoexponential fit of the fluorescence decay curves at different light intensities (Fig. 5b). In contrary to dark decay rates, $k_{\mathrm{D}}$, the rates of light adaptation, $k_{\mathrm{L}}$, depend on light intensity and follow a linear dependence. Remarkably, the interception of the $k_{\mathrm{L}}$ versus $I$ function is different from $k_{\mathrm{D}}$ in several bacterial strains indicating changes of the quenching parameters upon

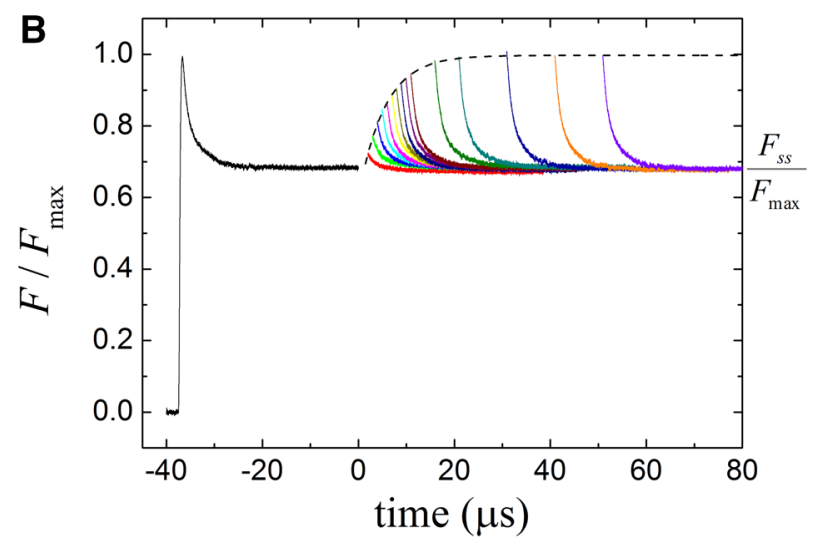

of the parameters given in the text. Panel $B$ the fluorescence kinetics induced by the first laser flash of $40 \mu$ s duration was interrupted by dark periods of variable durations and continued by excitation of a second flash that had the same intensity as the first one. The fluorescence levels were referred to the maximum fluorescence level $\left(F_{\max }\right)$ obtained after the first flash. $F_{\mathrm{SS}}$ denotes the steady-state level of quenched fluorescence at the highest light intensity 


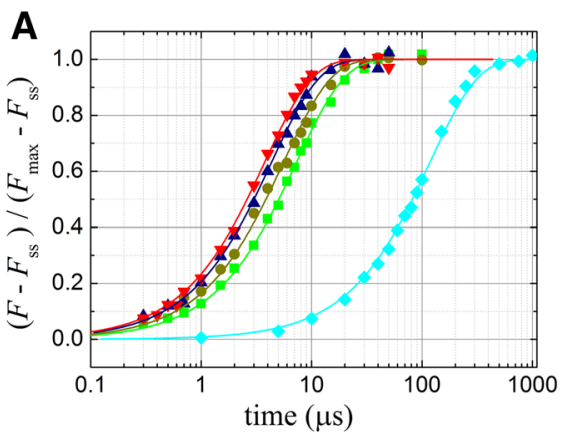

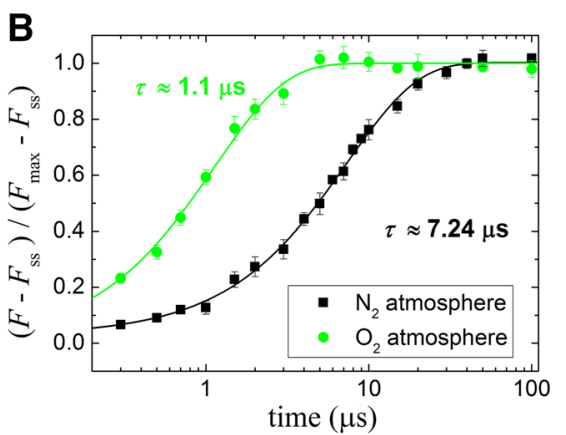

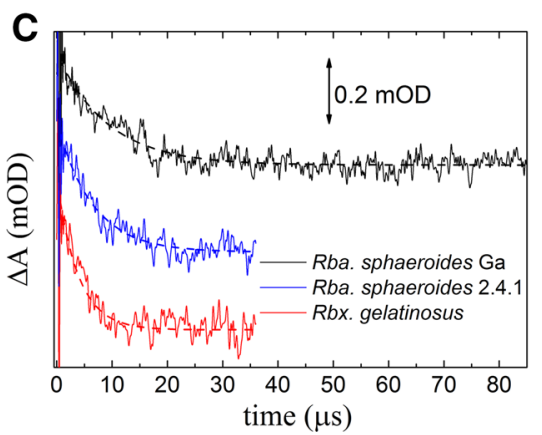

Fig. 4 a Kinetics of normalized fluorescence due to triplet states of different bacteria strains (lifetimes): inverted filled triangle Thio. roseopersicina $(3.7 \mu \mathrm{s})$, filled triangle Rvx. gelatinosus $(4.4 \mu \mathrm{s})$, filled circle Rba. sphaeroides $2.4 .1(5.8 \mu \mathrm{s})$, filled square Rba. sphaeroides $\mathrm{Ga}(7.2 \mu \mathrm{s})$, and filled diamond Rba. sphaeroides R-26 (120 $\mu \mathrm{s})$ containing spirilloxanthin $(n=13)$, spheroidenone $(n=11)$, spheroidene $(n=10)$, neurosporene $(n=9)$, and no carotenoid, respectively (see
Fig. 3 for details). b Normalized dark decay of the triplet state of Rba. sphaeroides $\mathrm{Ga}$ under anaerobic condition and under oxygen saturation. c Transient absorption changes $\Delta A$ of the (Car) triplet state at room temperature, induced by laser excitation. The traces are recorded at $540 \mathrm{~nm}$ (Rba. sphaeroides 2.4.1), $520 \mathrm{~nm}$ (Rba. sphaeroides $\mathrm{Ga})$, and $600 \mathrm{~nm}(R v x$. gelatinosus) under anaerobic conditions

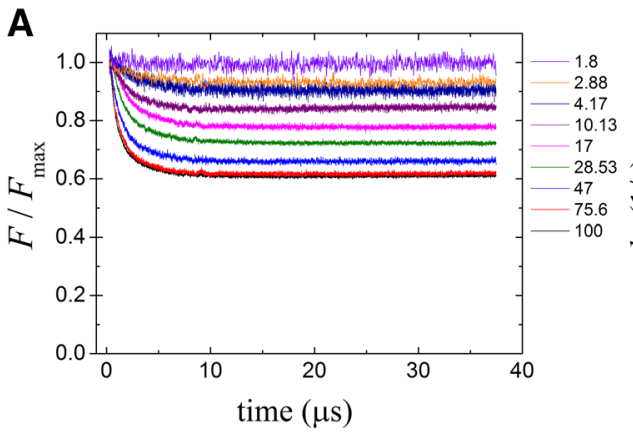

Fig. 5 Quenching of the BChl fluorescence at different laser intensities in light-adapted cells of Rba. sphaeroides (blocked photochemistry). Panel $A$ the fluorescence decays to a steady-state level within $40 \mu$ s of excitation. Inset attenuated light intensities. Panel $B$ the rate constants of fluorescence decay in the light (see panel $A$ ) versus laser light intensity $I$ that is identified as the photochemical rate constant

dark-light transition. The steady-state level of fluorescence quenching depends also on the intensity of the exciting light but deviates significantly from linearity in the intensity range used in our study (Fig. 5c).

\section{Triplet lifetimes of carotenoids of different conjugation lengths in intact cells}

The double-flash method enables the precise determination of the dark lifetime of carotenoid triplets in different bacterial strains. As the bacteria contain different carotenoids of variable content, the observed rate constant of the carotenoid triplet relaxation is the sum of rate constants weighted by the fraction of the corresponding carotenoid in the strain $k_{\mathrm{T}}=\sum_{n} k_{\mathrm{T}, n} \times \mathrm{Car}_{n}$, where $\sum_{n} \mathrm{Car}_{n}=1$ and $n$ denote the number of conjugated double bonds in the carotenoid chain. Taking the carotenoid content of the different strains measured in dark-adapted sample. The slope of the straight line corresponds to the efficiency of triplet generation. The rate constant of ${ }^{3}$ Car measured in the dark (see Fig. 3b) is also indicated. Panel $C$ light intensity dependence of the yield of BChl fluorescence quenching by ${ }^{3} \mathrm{Car}$

used in this study (Table 1), we can derive the dark triplet lifetimes of the carotenoids of various chain lengths. The representation of $\ln k_{\mathrm{T}}$ as a function of $(2 n+1) / n^{2}$ offers straight line (Fig. 6a). Taking into account the uncertainties of the carotenoid contents of the strains and of the measured triplet lifetimes, the comparison of the calculated and the observed triplet lifetimes in the different bacterial strains is quite satisfactory (Fig. 6b). Slight but systematic deviation can be seen for Rvx. gelatinosus whose reason is unclear. The derived Car triplet lifetime decreases when $n$ increases (Fig. 6a) which is in accord with the decrease in the energy gap between the triplet and singlet ground states. Carotenoids with longer conjugated chain have lower energy triplet states and so are energetically more likely to be quenched by oxygen triplets. Therefore, carotenoids with shorter triplet lifetimes will also fulfill this protective function with the same yield. The dependence similarly follows a linear 


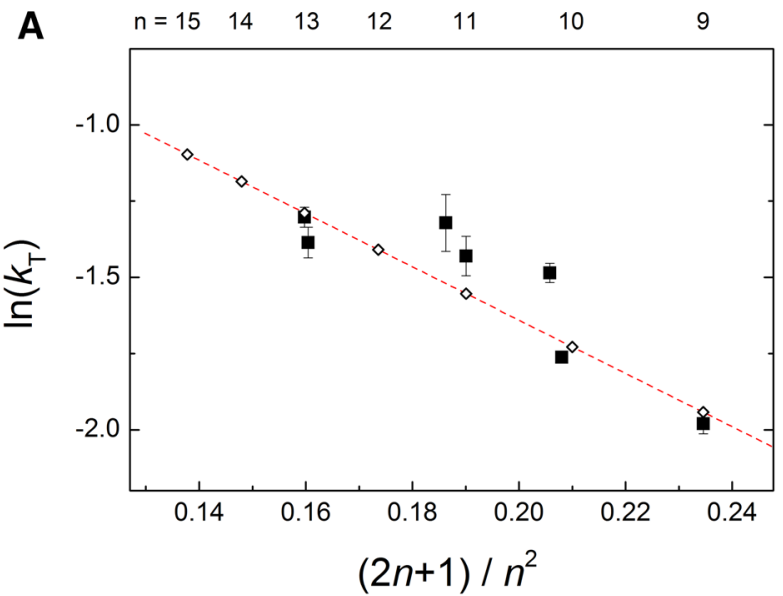

Fig. 6 Triplet relaxation rate constants $\left(k_{\mathrm{T}}\right)$ of carotenoids of different conjugation lengths $(n)$ in intact cells of photosynthetic bacteria. Panel A triplet rate constants for carotenoids determined from set of linear equations constructed from carotenoid components and from measured triplet lifetimes of the different strains listed in Table 1

relationship in this representation as was found for triplet states of selected carotenoids in organic solutions and LH preparations (Kakitani et al. 2007a), or for singlet excited states in LH2 preparation (Niedzwiedzki et al. 2015).

\section{Photochemical and carotenoid triplet quenchers act in parallel}

The photoprotection function of carotenoid triplets requires that carotenoid triplets will be formed only after completion of the photochemistry, when there is need to quench the BChl triplets generated in excess light (as would be predicted by the series model of photochemical and triplet quenchers of BChl fluorescence). Thus, while the photochemistry takes place, the excitation would be utilized for charge separation in the open $\mathrm{RC}$ and not for $\mathrm{BChl}$ triplet formation that should be protected by the carotenoid triplets. In contrast to what the series model would predict, data presented in Fig. 7 demonstrate that carotenoid triplets are still created during the photochemical rise and they are competitive to the primary photochemistry, consistent with the parallel model. As far as the experimental support concerns, the fluorescence induction is interrupted and continued by a second flash after variable dark intervals. Due to the photochemical nature of the fluorescence rise, the fluorescence would be continued from the same level where it was terminated after the first flash. This can be observed with a weak excitation when the open RC is the only fluorescence quencher. In contrast, with strong excitation, the fluorescence will start from a higher energy level than at the termination of the first flash, and the difference (and shape) will be more pronounced with an increase in the duration of

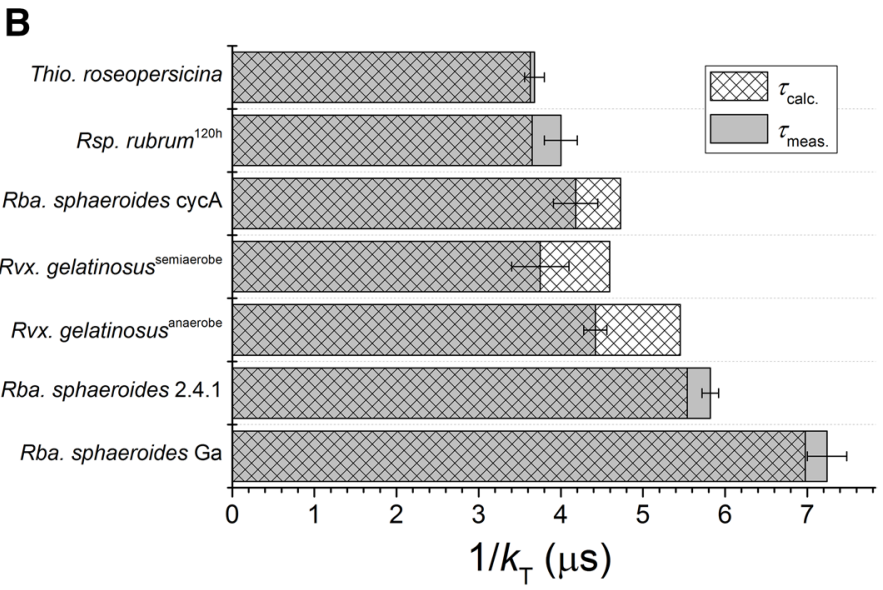

(open squares). Triplet rate constants of the bacteria calculated from the weighted average of the corresponding carotenoids hosted by the different strains (black squares). Panel B comparison of measured and calculated carotenoid triplet relaxation rate constants in different strains

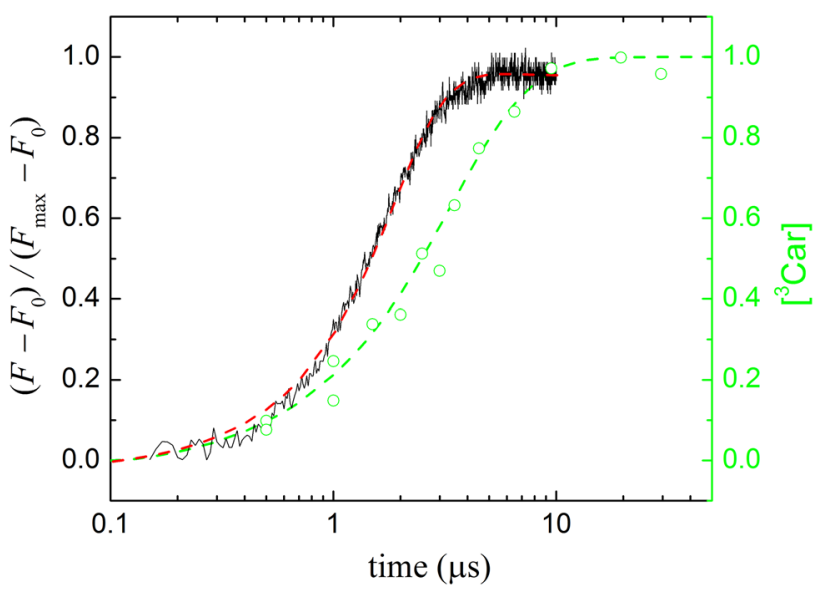

Fig. 7 Simultaneous measurement of the rise of the normalized variable BChl fluorescence (induction) and carotenoid triplet $\left({ }^{3} \mathrm{Car}\right)$ formation (triplet quenching) in whole cells of Rba. sphaeroides upon $10 \%$ laser light excitation. The ${ }^{3} \mathrm{Car}$ content at selected time was determined from the initial rise of the fluorescence at the onset of the second flash in a double-flash experiment (see Fig. 3b). Both kinetics saturate but the ${ }^{3} \mathrm{Car}$ suffers some delay relative to the fluorescence induction. The two kinetics are normalized to the same value

the dark interval between the flashes. This is a clear indication of the presence of another fluorescence quencher during the fluorescence induction. The carotenoid triplet formation is time-shifted from the photochemical rise showing that the two light-induced quenching processes are competitive and the rate of carotenoid triplet formation is smaller than that of the closure of the RC. The ratio of the two rates can be computed to obtain the yield of carotenoid triplet formation relative to that of photochemistry. 


\section{Discussion}

While the mechanism of generation of triplet-state carotenoids from the special-pair BChls in the RC has been extensively studied, the production of ${ }^{3} \mathrm{Car}$ via triplet energy transfer from ${ }^{3} \mathrm{BChl}$ in the $\mathrm{LH}$ complexes and membranes has been investigated less extensively. Moreover, few kinetic studies have been published on carotenoid triplets in intact cells. Here, the function of ${ }^{3} \mathrm{Car}$ was tracked under a variety of conditions. In an attempt to understand our results, we will focus on three elements: (1) the kinetics of generation and consumption of triplets in the pigment bed, (2) the dependence of ${ }^{3} \mathrm{Car}$ decay rate $\left(k_{\mathrm{T}}\right)$ on conjugation length $(n)$, and (3) the difference between $k_{\mathrm{T}}$ as measured under dark and light conditions.

\section{Migration and interaction of singlet and triplet excitons in the antenna}

Our experiments (Fig. 3a) showed that the fluorescence yield of BChls was controlled by two competitive fluorescence quenchers of open RC and carotenoid triplets. Additionally, it was demonstrated that the carotenoid triplets were produced in parallel with the closure of the RCs and not after establishment of photochemistry (Fig. 7). To understand the observed changes of the fluorescence induction, and to relate these to structural and functional aspects of the antenna, a simple phenomenological model (the lake model) is used for the description of the kinetics of singlet and triplet excitons in the antenna of bacteria. The singlet excitons of BChl* $\left(\varepsilon_{\mathrm{S}}\right)$ are generated by absorbed light (intensity, $I$ ) and can disappear via collisions with open RC and with carotenoid triplets

$\frac{d}{d t} \varepsilon_{\mathrm{S}}=I-k_{\mathrm{loss}} \times \varepsilon_{\mathrm{S}}-k_{\mathrm{p}} \frac{1-x_{\mathrm{RC}}}{1-p \times x_{\mathrm{RC}}} \times \varepsilon_{\mathrm{S}}-k_{\mathrm{tr}} \times x_{\mathrm{Car}} \times \varepsilon_{\mathrm{S}}$,

where $k_{\text {loss }}=k_{\mathrm{fl}}+k_{\mathrm{ISC}}+k_{\text {heat }}$ (see Fig. 2), $k_{\mathrm{p}}$ and $k_{\mathrm{tr}}$ denote the rate constants of consumption of excitons by spontaneous deactivation (fluorescence, intersystem crossing, and heat), photochemical conversion, and carotenoid triplet quenching, respectively. Here $x_{\mathrm{RC}}$ and $x_{\mathrm{Car}}$ are the fractions of closed $\mathrm{RCs}$ and of triplet forms of carotenoids $\left({ }^{3} \mathrm{Car}\right)$, respectively. The pseudo-monomolecular rate constants, $k_{\mathrm{p}}$ and $k_{\text {tr }}$ are the products of the corresponding bimolecular rate constants and total concentrations of the species $\left[\mathrm{RC}_{\mathrm{open}}\right]$ and $\left[{ }^{3} \mathrm{Car}\right]$, respectively. It is taken into account that the collision cross section of the fraction of open RCs $\left(1-x_{\mathrm{RC}}\right)$ is enhanced by a factor of $1 /\left(1-p \times x_{\mathrm{RC}}\right)$ due to the energetic cooperativity of the photosynthetic units (de Rivoyre et al. 2010). The triplet excitons $\left(\varepsilon_{\mathrm{T}}\right)$ are generated by singlet excitons via intersystem crossing (rate constant $k_{\mathrm{ISC}}$ ) and disappear by triplet-triplet energy transfer from ${ }^{3} \mathrm{BChl}$ to ${ }^{3} \mathrm{Car}$ with rate constant of $k_{\mathrm{Car}}$ $\frac{d}{d t} \varepsilon_{\mathrm{T}}=k_{\mathrm{ISC}} \times \varepsilon_{\mathrm{S}}-k_{\mathrm{Car}} \times \varepsilon_{\mathrm{T}}$.

As the carotenoid is excited through the $\mathrm{BChl}^{*}$ and not directly, the population of the ${ }^{3} \mathrm{Car}$ state should be exclusively the result of the T-T energy transfer from ${ }^{3} \mathrm{BChl}$. Thus, the singlet-triplet fission of carotenoid excitation ${ }^{1} \mathrm{Car} *{ }^{3} \mathrm{Car}+{ }^{3} \mathrm{Car}$ can be disclosed (Gradinaru et al. 2001; Klenina et al. 2013, 2014). The kinetics of ${ }^{3} \mathrm{Car}$ is determined by production from ${ }^{3} \mathrm{BChl}$ and spontaneous decay with rate constants $k_{\mathrm{Car}}$ and $k_{\mathrm{T}}$, respectively, as follows:

$\frac{d}{d t} x_{\mathrm{Car}}=k_{\mathrm{Car}} \times \varepsilon_{\mathrm{T}}-k_{\mathrm{T}} \times x_{\mathrm{Car}}$.

The losses of the singlet and triplet excitons by collision are not included in Eqs. (3) and (4), because the singlet excitons are quenched by triplets without changing the triplet concentrations: $\mathrm{BChl}{ }^{*}+{ }^{3} \mathrm{BChl} \rightarrow \mathrm{BChl}+{ }^{3} \mathrm{BChl}$ or $\mathrm{BChl} *+{ }^{3} \mathrm{Car} \rightarrow \mathrm{BChl}+{ }^{3} \mathrm{Car}$ [singlet $\rightarrow$ triplet fusion (Mauzerall 1976)]. The kinetics of closure of the open RC is governed by the photochemical process

$\frac{d}{d t}\left(1-x_{\mathrm{RC}}\right)=-k_{\mathrm{p}} \frac{1-x_{\mathrm{RC}}}{1-p \times x_{\mathrm{RC}}} \times \varepsilon_{\mathrm{S}}$.

Equations (2, 3, 4, and 5) offer solutions for the kinetics of the unknown variables $\varepsilon_{\mathrm{S}}, \varepsilon_{\mathrm{T}}, x_{\mathrm{RC}}$, and $x_{\mathrm{Car}}$ from the observed yield of $\mathrm{BChl}$ fluorescence

$\Phi=\frac{k_{\mathrm{fl}} \times \varepsilon_{\mathrm{S}}}{I}$

The series of fluorescence induction kinetics excited by attenuated light intensities could be fitted with the following set of parameters (Rba. sphaeroides, Fig. 3a): $p=0.15$, $I(100 \%)=1 /(25 \mathrm{~ns}), k_{\mathrm{T}}=1 /(3.47 \mu \mathrm{s} \pm 2.1 \mu \mathrm{s}), k_{\text {loss }}=1 /$ (48 ps $\pm 18 \mathrm{ps}), k_{\mathrm{tr}}=1 /(18 \mathrm{ps} \pm 5 \mathrm{ps}), k_{\mathrm{fl}}=1 /(1 \mathrm{~ns} \pm 0.2 \mathrm{~ns})$, $k_{\text {Car }}=1 /(6.7 \mathrm{~ns} \pm 17 \mathrm{ps}), k_{\mathrm{ISC}}=1 /(16.7 \mathrm{~ns} \pm 0.2 \mathrm{~ns}), k_{\mathrm{p}}=1 /$ (41 ps $\pm 10 \mathrm{ps}$ ). The match between the set of measured and calculated kinetics over broad time (intensity) region is satisfactory indicating that the exciton migration model is an appropriate approach to understand the basic processes of generation and relaxation of carotenoid triplets in intact cells of photosynthetic bacteria. From these data we obtained a maximum yield of BChl fluorescence $\Phi_{\max }=k_{\mathrm{fl}} / k_{\text {loss }} \approx 5 \%$ and yield of initial (constant) fluorescence $\Phi_{0}=k_{\mathrm{fl}} /\left(k_{\text {loss }}+k_{\mathrm{p}}\right) \approx 2.1 \%$.

The kinetics and stationary level of light-induced carotenoid triplet production can be derived from the model described by Eq. (2) through Eq. (5). According to Eq. (4), the steady-state level of carotenoid triplets will be established with a rate constant of

$k_{\mathrm{T}}=k_{\mathrm{L}}+\frac{k_{\mathrm{ISC}} \times k_{\mathrm{tr}} \times I}{k_{\text {loss }}^{2}}$ 
in the absence of photochemical quenching $(x=1)$ and under stationary light excitation. The same rate constant characterizes the drop of $\varepsilon_{\mathrm{S}}$ and $\varepsilon_{\mathrm{T}}$ from initial values of $I / k_{\text {loss }}$ and $I / k_{\text {loss }} \cdot k_{\mathrm{ISC}} / k_{\mathrm{Car}}$, respectively. The measured values for $k_{\mathrm{T}}$ increase linearly with light intensity, as was demonstrated in our experiments (Fig. 5b). The slope of the light intensity dependence does not characterize the yield of carotenoid triplet formation $\left(k_{\mathrm{ISC}} / k_{\text {loss }}\right)$ relative to that of the primary photochemistry only but the rate constant of quenching $\left(k_{\mathrm{tr}}\right)$ of ${ }^{3} \mathrm{BChl}$ via ${ }^{3} \mathrm{Car}$, as well. Their product can be interpreted as the effectiveness of the carotenoid triplet protection mechanism: the steeper the slope of the linear $k_{\mathrm{T}}$ versus $I$ function, the more effective the photoprotective function of the carotenoid triplet. Therefore, based on the magnitude of the slope, the carotenoid triplets in different bacterial strains can be classified according to their role in photoprotection (Table 1).

Besides the slope, the $y$-intercept of the straight line in Eq. (7) is also informative. It was observed that the initial value $k_{\mathrm{L}}\left(y\right.$-intercept) differed significantly from $k_{\mathrm{D}}$ in many of the bacterial species studied here. Based on the manner of their experimental determination, the rate constants can be termed "light" and "dark decay" constants. In each case, $k_{\mathrm{L}}$ was observed to be higher than or equal to $k_{\mathrm{D}}$. Therefore, we conclude that the slope of the linear function described in Eq. (7) should decrease upon transition from dark to light conditions. The change of the slope can be considered in physical terms as an accommodation of the BChl-carotenoid pigment complex to the appearance of (singlet-triplet) excitons in the antenna system. The transition takes place within a small intensity range after initiation of the light excitation. Although the slope and the intercept of the straight line (i.e., the difference between $k_{\mathrm{L}}$ and $k_{\mathrm{D}}$ ) can be determined with high accuracy, the decrease in the slope under conditions of low light intensity is difficult to measure. About one order of magnitude decrease in the slope in this narrow range can be estimated which indicates that the carotenoid triplet is about ten times more photoprotective in the dark than in the light.

The observed steady-state quenching of BChl fluorescence due to carotenoid triplet at light intensity $I$ can be expressed as

$\Phi=\Phi_{\max } \times \frac{\sqrt{1+\frac{4 I}{I_{\text {crit }}+I}}-1}{\frac{2 I}{I_{\text {crit }}+I}}$,

where the critical light intensity is $I_{\text {crit }}=\frac{k_{\text {loss }}^{2} \times k_{\mathrm{L}}}{k_{\mathrm{IS}} \times k_{\mathrm{tr}}}$. At this light intensity, the fluorescence level drops to $(\sqrt{ } 3-1=) 73 \%$ of that measured in the absence of quenching $\left(\Phi_{\max }=k_{\mathrm{fl}} / k_{\text {loss }}\right.$, i.e., $27 \%$ will be quenched). The intensity dependence of the steady-state level of carotenoid triplet quenching described by Eq. (8) shows very good agreement with the experimental data (Fig. 5c). Under our conditions, we were able to approach or even to exceed the critical light intensity, therefore the least-square fit of Eq. (8) to the data offered reliable values of $I_{\text {crit }}$ in the various bacterial strains (see Table 1). The critical light intensity can be related to the effectiveness of carotenoid triplet protection function: it is inversely proportional to the rate constant (and yield) of formation $k_{\mathrm{ISC}} / k_{\text {loss }}^{2}$, to the second-order rate constant of quenching $k_{\text {tr }}$, and to the lifetime $1 / k_{\mathrm{T}}$ of the carotenoid triplet. The larger these quantities are, the lower the light intensity needed to quench the $\mathrm{BChl}$ fluorescence or to protect the ${ }^{3} \mathrm{BChl}$ species from photodamage.

\section{Triplet decay rates of carotenoids of different conjugation lengths in intact cells}

The (dark) lifetimes of carotenoid triplets $\left(1 / k_{\mathrm{D}}\right)$ in various photosynthetic bacteria were determined in vivo by $\mathrm{BChl}$ fluorescence quenching experiments and decomposed into components that we attributed to carotenoids having different numbers $(n)$ of conjugated double bonds. The observed lifetime decreased (i.e., the rate constant of triplet deactivation $\left(\mathrm{T}_{1} \rightarrow \mathrm{S}_{0}\right.$ ) increased) when the number of conjugated double bonds ( $n$ ) increased (Fig. 6). This is in accordance with the energy-gap law that arises from the vibrational overlap of the $T_{1}$ and $S_{0}$ states so that the non-radiative decay rate becomes a function of the vibrationally induced electronic coupling term (C) and the Franck-Condon factor (Englman and Jortner 1970). In the weak coupling limit when the relative displacement of the two adiabatic potential surfaces is small

$k_{\mathrm{T}}=\frac{2 \pi}{\hbar} C^{2} \frac{\exp \left(-\frac{\delta^{2}}{2}\right)}{\sqrt{2 \pi \times \Delta E \times \hbar \omega_{\mathrm{M}}}} \times \exp \left(-\gamma \frac{\Delta E}{\hbar \omega_{\mathrm{M}}}\right)$.

Here $\Delta E$ is the energy gap between the $\mathrm{T}_{1}$ and $\mathrm{S}_{0}$ states; $\omega_{M}$ is the maximum and dominant vibrational frequency available in the system; $\delta$ is the displacement of the potential minimum along the normal coordinate upon transition; and $\gamma$ is a term that can be expressed in terms of molecular parameters $\gamma=\ln \frac{2 \times \Delta E}{\delta^{2} \times \hbar \omega_{\mathrm{M}}}-1(\gamma>0)$.

The energy gap between the lowest occupied molecular orbital (LUMO) and the highest occupied molecular orbital (HOMO) can be calculated by the delocalization of the $\pi$-electrons along the whole linear chain

$\Delta E=\frac{h^{2}}{8 m L^{2}}\left(n_{\mathrm{LUMO}}^{2}-n_{\mathrm{HOMO}}^{2}\right)$.

Here $\mathrm{L}=n \times l$, the length of the chain $(l \sim 2.88 \AA$ denotes the length of the elementary unit consisting of a double $\mathrm{C}=\mathrm{C}$ and single $\mathrm{C}-\mathrm{C}$ bonds); $h$ is the Planck constant; $m$ is the mass of an electron; $n_{\mathrm{LUMO}}=n+1$; and $n_{\mathrm{HOMO}}=n$. 
Substituting Eq. (10) into Eq. (9) and neglecting the change in $-\ln \sqrt{\Delta E}$, a linear relationship between $\ln \left(k_{\mathrm{T}}\right)$ and $(2 n+1) / n^{2}$ can be obtained. The slope of the straight line is $-\gamma / \hbar \omega_{\mathrm{M}} \times h^{2} / 8 m l^{2}$ and the intercept is determined by $\ln (\mathrm{C})$ and $-\delta^{2}$. Indeed, our points fit a straight line (see Fig. 6a). The longer the chain, the smaller the energy gap between $T_{1}$ and $\mathrm{S}_{0}$ and the higher the rate of triplet relaxation.

The slight drop in the carotenoid triplet energy upon increase of $n$ leads to opposite tendencies of efficiency of ${ }^{3}$ Car protection. On one hand, it will cause a small increase of the energy gap between ${ }^{3} \mathrm{BChl}$ and ${ }^{3} \mathrm{Car}$. The slow ${ }^{3} \mathrm{BChl}$ to ${ }^{3} \mathrm{Car} \mathrm{T}-\mathrm{T}$ energy transfer on the ns time range [4.8-16 ns in LH2 of Allochromatium vinosum (Magdaong 2015)], $2.0 \mathrm{~ns}$ (Rondonuwu et al. 2004) and $16.7 \mathrm{~ns}$ (Kosumi et al. 2016) involves the exchange of two electrons of different spin and energy [Dexter mechanism, (Koyama and Kakitani 2006)]. As the rate of electron transfer (exchange) depends exponentially on the free energy difference between the initial and final states (Marcus theory), the rate of ${ }^{3} \mathrm{BChl}$ quenching will increase with increase in $n$. On the other hand, the lifetime of ${ }^{3} \mathrm{BChl}$ state remains $\sim 10$ times longer in the antenna complexes $[\sim 100 \mu$ s in solution of the monomeric BChl $a$ (Niedzwiedzki and Blankenship 2010), $\sim 80 \pm 5 \mu$ s for the B850 complex in Rba. sphaeroides strain R-26.1 (Farhoosh et al. 1994)], and in RCs [13 $\mu$ s (at 298 K) obtained from a carotenoidless mutant of Rba. sphaeroides R26 (Mandal et al. 2017)] than the lifetime of ${ }^{3} \mathrm{Car}$. Thus less time will be available to quench ${ }^{3} \mathrm{BChl}$ in the form of $\mathrm{BChl}$ triplet-Car triplet annihilation that would yield excited singlet $\mathrm{BChl}\left(\mathrm{Q}_{\mathrm{y}}\right)$ state. In this way, ${ }^{3} \mathrm{Car}$ performs a lightharvesting function besides the photoprotective function. Depending on the balance of these tendencies, the outcome can be either positive or negative. At moderate intensity of light excitation, the decrease of the ${ }^{3} \mathrm{Car}$ lifetime is the weaker factor, therefore the ${ }^{3} \mathrm{BChl}$ can be effectively quenched by ${ }^{3} \mathrm{Car}$, and the quenching efficiency is higher in Cars having a longer conjugated chain. A nice piece of evidence of controlled photoprotection of carotenoid was demonstrated in Rba. sphaeroides (Slouf et al. 2012).

According to Eq. (9), the term $\omega_{\mathrm{M}}$ primarily defines the dependence of $k_{\mathrm{T}}$ on the length of hydrocarbon chain of the carotenoids: the larger $\omega_{\mathrm{M}}$ is, the greater the nonradiative decay rate becomes. For aromatic hydrocarbons the $\mathrm{C}-\mathrm{H}$ stretching mode with a vibrational energy of $\hbar \omega_{\mathrm{M}} \approx 3000 \mathrm{~cm}^{-1}\left(=6 \times 10^{-20} \mathrm{~J}\right)$, we consider that this stretching mode will be particularly efficient at promoting non-radiative decay of excited triplet carotenoids in photosynthetic bacteria. The $\gamma$ molecular parameters for various hydrocarbons were estimated to vary in the range 1.31-0.50 (Englman and Jortner 1970). Thus, taking $h^{2} /$ $\left(8 m l^{2}\right)=7.3 \times 10^{-19} \mathrm{~J}$, the slope of the straight line in Fig. 6a can be estimated between -16 and -6 . Indeed, we got -8.7 which shows nice accordance with the predictions.
The intrinsic $T_{1}$ energies of the carotenoids, however, are significantly different in solution compared to the natural environments of bacteria. Additionally, even slight differences were reported in various reconstituted LH1 and LH2 complexes and LH1 and RC components of the RC-LH1 complex (Kakitani et al. 2007a). Regarding Eq. (9), the shift (smaller intercept of the straight line) can be attributed to different electronic (spin-orbit) coupling between the initial and final states of the transition $(C)$ and/or to displacement of the potential energy surface minima $(\delta)$ for the two states involved in the transition. The consideration of the former possibility has been emphasized and sometimes overweighted in the studies on carotenoid triplets in photosynthetic bacteria.

The tight connection between structure and photoprotective function of carotenoids has led to the idea of natural selection of configurations and conjugation lengths of Cars by the antenna and the RC (Kakitani et al. 2007b; Koyama et al. 2007): in LH2, shorter conjugated chain in the all-trans configuration is selected for the light-harvesting function, whereas in the RC a longer conjugated chain in the 15-cis configuration is used for the photoprotective function. According to our view, the photoprotective role of Cars is not restricted to those in the RC but very effective protection takes place in the antenna, as well. At high light intensity, the $\mathrm{RC}$ is closed for a longer period of time to accept excitation. As the closed RC represents a shallow trap for the excitons, they return readily to the antenna where they should be quenched by the carotenoids. Thus, the observed classification of Car according to structure (configuration and chain length) in the photosynthetic apparatus cannot be solely determined by the photoprotective/light-harvesting function of these chromophores. Similar conclusions can be drawn from experiments of Bautista (Bautista et al. 1998) who found that the spectroscopic properties and the excited-state dynamics were not very different between RCs from Rba. sphaeroides R26.1 containing incorporated locked-15-cis-spheroidene and those for native RC from Rba. sphaeroides 2.4 .1 containing (unlocked) 15-cis-spheroidene. They argue that the cis-isomer conformation of spheroidene in RC of Rba. sphaeroides 2.4 .1 is primarily determined by the structure or assembly of the RC protein.

Our results support the energy-gap law and earlier findings with carotenoids in organic solvents (Mathis and Kleo 1973; Bensasson et al. 1976) or in isolated photosynthetic complexes (Koyama and Fujii 1999). The novelty of our investigation is to establish the linear relationship between $\ln \left(k_{\mathrm{T}}\right)$ and $(2 n+1) / n^{2}$ for carotenoids triplets in whole cells and with a wide range of conjugation length, and to demonstrate the role of the dynamics of the carotenoid (flexibility, twisting, etc.) to provide a pathway for radiationless deactivation of the triplet state. 


\section{Photoprotection: conformational dark-light switch for increased triplet dissipation in antenna}

Our observation that the carotenoid triplet dissipation rate increased in the light $\left(k_{\mathrm{L}}>k_{\mathrm{D}}\right)$ is clearly consistent with the physiological demand on the bacterium for enhanced effectivity of photoprotection. We will discuss how earlier findings will support this view and what molecular changes may facilitate this function.

The back-transfer from the RC to LH1 occurs even faster than the forward transfer LH1 $\rightarrow$ RC (Damjanovic et al. 2000). Excess excitation that is not used in a RC to induce an electron transfer is transferred back to LH1 and the antenna LH2 complexes, where it is either transferred on to another $\mathrm{RC}$ or dissipated. This organization sets all of the carotenoids (not only those bound to the RC) in the frontline of photoprotection. In contrast to algae and higher plants, in the vast majority of light-harvesting proteins from purple photosynthetic bacteria, the triplet state is mainly (if not totally) localized on the carotenoid (and not on BChl) molecule (Maxime and van Grondelle 2012; Angerhofer et al. 1995). This localization of the triplet state is associated with a relatively slow $\mathrm{T}-\mathrm{T}$ transfer between the $\mathrm{BChl}$ and carotenoid molecules, in the 20-200 ns time scale. The carotenoids can effectively dissipate their triplet excitation energy and constitute an essential part of photoprotection in bacteria.

The introduction of two different dark $\left(1 / k_{\mathrm{D}}\right)$ and light $\left(1 / k_{\mathrm{L}}\right)$ lifetimes of carotenoid triplet might deserve consideration in relation to earlier reports of two (multiple) configurations of spheroidene in the RC of Rba. sphaeroides 2.4.1. in the ground state (Wirtz et al. 2007) and the excited triplet state (Kolaczkowski 1989; Kakitani et al. 2006). An unusual temporal evolution of the EPR spectra of ${ }^{3} \mathrm{Car}$ was detected in different pigment-protein complexes, and was interpreted as a result of significant differences in the rate of deactivation of spin sublevels of the Car triplet state (Klenina et al. 2013). They observed that relaxation to ground state occurred more quickly in the case of the RC $(8.5 \mu$ s in LH2 vs. $3.5 \mu \mathrm{s}$ in the RC). All these effects (structural alterations, heterogeneous decay pattern, etc.) can contribute to the observed difference of carotenoid triplet lifetimes in the dark and light states in some bacterial strains under our conditions but we prefer the possible slight structural modification of the BChl-Car protein complex in response to the presence of excitons in the light state of the antenna.

There are several reports on triplet exciton formation in native photosynthetic systems. In chlorosomes, the lightharvesting antenna from the green photosynthetic bacteria, whose core structure is self-assembled aggregates of BChl, long-lived triplet states were detected (Kim 2007). They were not quenched by oxygen and were identified as triplet excitons formed in closely packed BChls. The exciton coupling between the 18 pigments in B850 was large enough to cause significant delocalization (Alden et al. 1997) but the 9 BChls in the B800 band were much further apart and exhibited more localized excitations. In plant light-harvesting complexes, the triplet wave function is shared between the carotenoids and their adjacent chlorophylls but not in purple bacteria where the triplet is virtually fully located on the carotenoid molecule (Gall et al. 2011). A molecular mechanism which spreads the location of triplet wave function through neighboring pigments would accelerate the decay of the triplets and enhance the effectiveness of the photoprotection of BChl molecules. The creation of the carotenoid triplet states in solution occurs with detectable conformational changes or a light-induced conformational switch that takes the interacting pigments closer to each other would be a suitable molecular mechanism. Similar switching was recently described by single-molecule spectroscopy (Gall et al. 2015).

Our study supports the conclusion that the lifetime and photoprotective function of the carotenoid triplet state in intact cells depend not only on the energies and structure (conjugation chain length, configuration, electronic coupling) of the carotenoid triplet but also on the dynamics controlling the relaxation.

Acknowledgements This work was supported by GINOP-2.3.2-152016-00001, OTKA-K 112688, COST (CM1306), EFOP-3.6.2-162017, and Photosynthesis - Life from Light-Foundation (Hungary).

\section{References}

Alden RG, Johnson E, Nagarajan V, Parson WW, Law CJ, Cogdell RG (1997) Calculations of spectroscopic properties of the LH2 bacteriochlorophyll-protein antenna complex from Rhodopseudomonas acidophila. J Phys Chem B 101(23):4667-4680. doi:10.1021/Jp970005r

Angerhofer A, Bornhauser F, Gall A, Cogdell RJ (1995) Optical and optically detected magnetic-resonance investigation on purple photosynthetic bacterial antenna complexes. Chem Phys 194(23):259-274. doi:10.1016/0301-0104(95)00022-G

Asztalos E, Sipka G, Maróti P (2015) Fluorescence relaxation in intact cells of photosynthetic bacteria: donor and acceptor side limitations of reopening of the reaction center. Photosynth Res 124(1):31-44. doi:10.1007/s11120-014-0070-0

Bagyinka C, Kovacs KL, Rak E (1981) Localization of hydrogenase in the photosynthetic membrane of Thiocapsa roseopersicina. Acta Biochimica et Biophysica Hungarica 16(3-4):235-235

Bautista JA, Chynwat V, Cua A, Jansen FJ, Lugtenburg J, Gosztola D, Wasielewski MR, Frank HA (1998) The spectroscopic and photochemical properties of locked-15,15 '-cis-spheroidene in solution and incorporated into the reaction center of Rhodobacter sphaeroides R-26.1. Photosynth Res 55(1):49-65. doi:10.10 23/A: 1005955425420

Bensasson R, Land EJ, Maudinas B (1976) Triplet-states of carotenoids from photosynthetic bacteria studied by nanosecond ultraviolet and electron pulse irradiation. Photochem Photobiol 23(3):189193. doi:10.1111/j.1751-1097.1976.tb07240.x

Borland CF, Cogdell RJ, Land EJ, Truscott TG (1989) Bacteriochlorophyll $\alpha$-triplet state and its interactions with bacterial 
carotenoids and oxygen. J Photochem Photobiol B 3(2):237-245. doi:10.1016/1011-1344(89)80065-X

Breton J, Geacintov NE, Swenberg CE (1979) Quenching of fluorescence by triplet excited-states in chloroplasts. Biochim Biophys Acta 548(3):616-635. doi:10.1016/0005-2728(79)90069-0

Chi SC, Mothersole DJ, Dilbeck P, Niedzwiedzki DM, Zhang H, Qian P, Vasilev C, Grayson KJ, Jackson PJ, Martin EC, Li Y, Holten D, Hunter CN (2015) Assembly of functional photosystem complexes in Rhodobacter sphaeroides incorporating carotenoids from the spirilloxanthin pathway. Biochim Biophys Acta Bioenerg 1847(2):189-201. doi:10.1016/j.bbabio.2014.10.004

Claes H, Nakayama TOM (1959) Das photooxydative Ausbleichen von Chlorophyll in vitro in Gegenwart von Carotinen mit verschiedenen Chromophoren Gruppen. Z Naturforsch 14b:746-747

Cogdell RJ (1978) Carotenoids in photosynthesis. Philos Trans R Soc B 284(1002):569-579. doi:10.1098/rstb.1978.0090

Cogdell RJ (1986) Light-harvesting complexes in purple photosynthetic bacteria. In: Staehelin IA, Arntzen CJ (eds) Photosynthesis III, vol 19. Encyclopedia of plant physiology. Springer, Berlin, pp 252-259. doi:10.1007/978-3-642-70936-4

Cogdell RJ, Frank HA (1987) How carotenoids function in photosynthetic bacteria. Biochim Biophys Acta 895(2):63-79. doi:10.1016/ S0304-4173(87)80008-3

Cogdell RJ, Hipkins MF, Macdonald W, Truscott TG (1981) Energytransfer between the carotenoid and the bacteriochlorophyll within the B800-850 light-harvesting pigment-protein complex of Rhodopseudomonas sphaeroides. Biochim Biophys Acta 634(1):191202. doi:10.1016/0005-2728(81)90138-9

Cogdell RJ, Howard TD, Bittl R, Schlodder E, Geisenheimer I, Lubitz W (2000) How carotenoids protect bacterial photosynthesis. Philos Trans R Soc B 355(1402):1345-1349. doi:10.1098/ rstb.2000.0696

Cogdell RJ, Gardiner AT, Roszak AW, Law CJ, Southall J, Isaacs NW (2004) Rings, ellipses and horseshoes: how purple bacteria harvest solar energy. Photosynth Res 81(3):207-214. doi:10.1023/ B:PRES.0000036883.56959.a9

Damjanovic A, Ritz T, Schulten K (2000) Excitation energy trapping by the reaction center of Rhodobacter sphaeroides. Int J Quantum Chem 77(1):139-151. doi:10.1002/ (SICI) 1097-461X(2000)77:1<139::AID-QUA13>3.0.CO;2-S

Daviso E, Prakash S, Alia A, Gast P, Neugebauer J, Jeschke G, Matysik $\mathrm{J}$ (2009) The electronic structure of the primary electron donor of reaction centers of purple bacteria at atomic resolution as observed by photo-CIDNP C-13 NMR. Proc Natl Acad Sci USA 106(52):22281-22286. doi:10.1073/pnas.0908608106

de Rivoyre M, Ginet N, Bouyer P, Lavergne J (2010) Excitation transfer connectivity in different purple bacteria: a theoretical and experimental study. Biochim Biophys Acta 1797(11):1780-1794. doi:10.1016/j.bbabio.2010.07.011

Englman R, Jortner J (1970) The energy gap law for radiationless transitions in large molecules. Mol Phys 18(2):145-164. doi:10.1080/00268977000100171

Farhoosh R, Chynwat V, Gebhard R, Lugtenburg J, Frank HA (1994) Triplet energy-transfer between bacteriochlorophyll and carotenoids in B850 light-harvesting complexes of Rhodobacter sphaeroides R-26.1. Photosynth Res 42(2):157-166. doi:10.1007/ Bf02187126

Farhoosh R, Chynwat V, Gebhard R, Lugtenburg J, Frank HA (1997) Triplet energy transfer between the primary donor and carotenoids in Rhodobacter sphaeroides R-26.1 reaction centers incorporated with spheroidene analogs having different extents of $\pi$-electron conjugation. Photochem Photobiol 66(1):97-104. doi:10.1111/j.1751-1097.1997.tb03144.x

Foote CS, Denny RW (1968) Chemistry of singlet oxygen. VII. Quenching by $\beta$-carotene. J Am Chem Soc 90:6233-6235. doi:10.1021/ja01024a061
Formaggio E, Cinque G, Bassi R (2001) Functional architecture of the major light-harvesting complex from higher plants. J Mol Biol 314(5):1157-1166. doi:10.1006/jmbi.2000.5179

Fraser NJ, Hashimoto H, Cogdell RJ (2001) Carotenoids and bacterial photosynthesis: the story so far.... Photosynth Res 70(3):249-256. doi:10.1023/A:1014715114520

Gall A, Berera R, Alexandre MT, Pascal AA, Bordes L, MendesPinto MM, Andrianambinintsoa S, Stoitchkova KV, Marin A, Valkunas L, Horton P, Kennis JT, van Grondelle R, Ruban A, Robert B (2011) Molecular adaptation of photoprotection: triplet states in light-harvesting proteins. Biophys J 101(4):934942. doi:10.1016/j.bpj.2011.05.057

Gall A, Ilioaia C, Kruger TP, Novoderezhkin VI, Robert B, van Grondelle R (2015) Conformational switching in a light-harvesting protein as followed by single-molecule spectroscopy. Biophys J 108(11):2713-2720. doi:10.1016/j.bpj.2015.04.017

Glaeser J, Klug G (2005) Photo-oxidative stress in Rhodobacter sphaeroides: protective role of carotenoids and expression of selected genes. Microbiology 151:1927-1938. doi:10.1099/ mic. $0.27789-0$

Gradinaru CC, Kennis JTM, Papagiannakis E, van Stokkum IHM, Cogdell RJ, Fleming GR, Niederman RA, van Grondelle R (2001) An unusual pathway of excitation energy deactivation in carotenoids: singlet-to-triplet conversion on an ultrafast timescale in a photosynthetic antenna. Proc Natl Acad Sci USA 98(5):2364-2369. doi:10.1073/pnas.051501298

Griffiths M, Sistrom WR, Cohenbazire G, Stanier RY, Calvin M (1955) Function of carotenoids in photosynthesis. Nature 176(4495):1211-1215. doi:10.1038/1761211a0

Hashimoto H, Fujii R, Yanagi K, Kusumoto T, Gardiner AT, Cogdell RJ, Roszak AW, Issacs NW, Pendon Z, Niedzwiedski D, Frank HA (2006) Structures and functions of carotenoids bound to reaction centers from purple photosynthetic bacteria. Pure Appl Chem 78(8):1505-1518. doi:10.1351/pac200678081505

Hawthornthwaite AM, Cogdell RJ (1991) Bacteriochlorophyll-binding proteins. In: Scheer H (ed) The Chlorophylls. CRC Press Inc., Boca Raton, pp 493-528

Hess S, Chachisvilis M, Timpmann K, Jones MR, Fowler GJS, Hunter CN, Sundstrom V (1995) Temporally and spectrally resolved subpicosecond energy transfer within the peripheral antenna complex (LH2) and from LH2 to the core antenna complex in photosynthetic purple bacteria. Proc Natl Acad Sci USA 92(26):12333-12337. doi:10.1073/pnas.92.26.12333

Hunter CN, Pennoyer JD, Sturgis JN, Farrelly D, Niederman RA (1988) Oligomerization states and associations of light-harvesting pigment protein complexes of Rhodobacter sphaeroides as analyzed by lithium dodecyl-sulfate polyacrylamide-gel electrophoresis. Biochemistry 27(9):3459-3467. doi:10.1021/ bi00409a050

Kakitani Y, Fujii R, Koyama Y, Nagae H, Walker L, Salter B, Angerhofer A (2006) Triplet-state conformational changes in 15-cisspheroidene bound to the reaction center from Rhodobacter sphaeroides 2.4.1 as revealed by time-resolved EPR spectroscopy: strengthened hypothetical mechanism of triplet-energy dissipation. BioChemistry 45(7):2053-2062. doi:10.1021/bi0511538

Kakitani Y, Akahane J, Ishii H, Sogabe H, Nagae H, Koyama Y (2007a) Conjugation-length dependence of the $\mathrm{T} 1$ lifetimes of carotenoids free in solution and incorporated into the LH2, LH1, RC, and RC-LH1 complexes: possible mechanisms of triplet-energy dissipation. BioChemistry 46(8):2181-2197. doi:10.1021/bi062237z

Kakitani Y, Fujii R, Hayakawa Y, Kurahashi M, Koyama Y, Harada J, Shimada K (2007b) Selective binding of carotenoids with a shorter conjugated chain to the LH2 antenna complex and those with a longer conjugated chain to the reaction center from Rubrivivax gelatinosus. BioChemistry 46(24):7302-7313. doi:10.1021/ bi602485x 
Kim H (2007) Discovery of novel photoprotection mechanisms in photosynthesis using optical spectroscopy and biosensor development. Purdue University, (Ph.D.)

Klenina IB, Makhneva ZK, Moskalenko AA, Kuz'min AN, Proskuriakov II (2013) Singlet-triplet excitation fission in light-harvesting complexes of photosynthetic bacteria and in isolated carotenoids. Biofizika 58(1):54-63. doi:10.1134/S0006350913010077

Klenina IB, Makhneva ZK, Moskalenko AA, Gudkov ND, Bolshakov MA, Pavlova EA, Proskuryakov II (2014) Singlet-triplet fission of carotenoid excitation in light-harvesting LH2 complexes of purple phototrophic bacteria. Biochemistry 79(3):235-241. doi:10.1134/ S0006297914030092

Kocsis P, Asztalos E, Gingl Z, Maróti P (2010) Kinetic bacteriochlorophyll fluorometer. Photosynth Res 105(1):73-82. doi:10.1007/ s11120-010-9556-6

Koepke J, Hu XC, Muenke C, Schulten K, Michel H (1996) The crystal structure of the light-harvesting complex II (B800-850) from Rhodospirillum molischianum. Structure 4(5):581-597. doi:10.1016/ S0969-2126(96)00063-9

Kolaczkowski SV (1989) On the mechanism of triplet energy transfer from the triplet primary donor to spheroidene in photosynthetic reaction centers from Rhodobacter sphaeroides, 2.4.1. Brown University, Providence, Rhode Island, (Ph.D.)

Kosumi D, Horibe T, Sugisaki M, Cogdell RJ, Hashimoto H (2016) Photoprotection mechanism of light-harvesting antenna complex from purple bacteria. J Phys Chem B 120 (5):951-956. doi:10.1021/acs.jpcb.6b00121

Koyama Y (1991) New trends in photobiology: structures and functions of carotenoids in photosynthetic systems. J Photochem Photobiol B 9(3-4):265-280. doi:10.1016/1011-1344(91)80165-E

Koyama Y, Fujii R (1999) Cis-Trans carotenoids in photosynthesis: configurations, excited-state properties and physiological functions. In: Frank HA, Young AJ, Britton G, Cogdell RJ (eds) The photochemistry of carotenoids. Advances in photosynthesis and respiration, vol 8. Kluwer Academic Publishers, Dordrecht, pp 161-188. doi:10.1007/0-306-48209-6_9

Koyama Y, Kakitani Y (2006) Mechanisms of carotenoid-to-bacteriochlorophyll energy transfer in the light harvesting antenna complexes 1 and 2: dependence on the conjugation length of carotenoids. In: Grimm B, Porra RJ, Rüdiger W, Scheer H (eds) Chlorophylls and bacteriochlorophylls. Advances in photosynthesis and respiration, vol 25. Springer, Dordrecht, pp 431-443. doi:10.1007/1-4020-4516-6_30

Koyama Y, Kuki M, Andersson PO, Gillbro T (1996) Singlet excited states and the light-harvesting function of carotenoids in bacterial photosynthesis. Photochem Photobiol 63(3):243-256. doi:10.1111/j.1751-1097.1996.tb03021.x

Koyama Y, Kakitani Y, Watanabe Y (2007) Photophysical properties and light-harvesting and photoprotective functions of carotenoids in bacterial photosynthesis: structural selections. In: Renger G (ed) Primary processes of photosynthesis, part 1: principles and apparatus, vol 8. RSC Publishing, Cambridge, pp 151-201. doi:10.1039/9781847558152-00151

Lang HP, Hunter CN (1994) The relationship between carotenoid biosynthesis and the assembly of the light-harvesting LH2 complex in Rhodobacter sphaeroides. Biochem J 298:197-205. doi:10.1042/ bj2980197

Magdaong NCM (2015) Spectroscopy and Photophysics of Carotenoids in Solution and in Light-harvesting Pigment-Protein Complexes. University of Connecticut, (Ph.D.)

Mandal S, Carey AM, Locsin J, Gao BR, Williams JC, Allen JP, Lin S, Woodbury NW (2017) Mechanism of triplet energy transfer in photosynthetic bacterial reaction centers. J Phys Chem B. doi:10.1021/acs.jpcb.7b03373

Maróti P (2008) Kinetics and yields of bacteriochlorophyll fluorescence: redox and conformation changes in reaction center of
Rhodobacter sphaeroides. Eur Biophys J 37(7):1175-1184. doi:10.1007/s00249-008-0300-5

Maróti P, Wraight CA (1988) Flash-induced H+ binding by bacterial photosynthetic reaction centers-comparison of spectrophotometric and conductimetric methods. Biochim Biophys Acta 934(3):314-328. doi:10.1016/0005-2728(88)90091-6

Maróti P, Asztalos E, Sipka G (2013) Fluorescence assays for photosynthetic capacity of bacteria. Biophys J 104(2):545a-545a. doi:10.1016/j.bpj.2012.11.3017

Mathis P, Kleo J (1973) The triplet state of $\beta$-carotene and of analog polyenes of different length. Photochem Photobiol 18:343-346. doi:10.1111/j.1751-1097.1973.tb06431.x

Mauzerall D (1976) Multiple excitations in photosynthetic systems. Biophys J 16(1):87-91. doi:10.1016/S0006-3495(76)85665-2

Maxime A, van Grondelle R (2012) Time-resolved FTIR difference spectroscopy reveals the structure and dynamics of carotenoid and chlorophyll triplets in photosynthetic light-harvesting complexes. In: Prof. Theophile T (ed) Infrared spectroscopy-life and biomedical sciences. InTech, Rijeka. doi:10.5772/36178

Monger TG, Parson WW (1977) Singlet-triplet fusion in Rhodopseudomonas sphaeroides chromatophores - probe of organization of photosynthetic apparatus. Biochim Biophys Acta 460(3):393-407. doi:10.1016/0005-2728(77)90080-9

Monger TG, Cogdell RJ, Parson WW (1976) Triplet states of bacteriochlorophyll and carotenoids in chromatophores of photosynthetic bacteria. Biochim Biophys Acta 449(1):136-153. doi:10.1016/0005-2728(76)90013-X

Niedzwiedzki DM, Blankenship RE (2010) Singlet and triplet excited state properties of natural chlorophylls and bacteriochlorophylls. Photosynth Res 106(3):227-238. doi:10.1007/s11120-010-9598-9

Niedzwiedzki DM, Dilbeck PL, Tang Q, Mothersole DJ, Martin EC, Bocian DF, Holten D, Hunter CN (2015) Functional characteristics of spirilloxanthin and keto-bearing analogues in light-harvesting LH2 complexes from Rhodobacter sphaeroides with a genetically modified carotenoid synthesis pathway. Biochim Biophys Acta 1847(6-7):640-655. doi:10.1016/j.bbabio.2015.04.001

Pan J, Lin S, Allen JP, Williams JC, Frank HA, Woodbury NW (2011) Carotenoid excited-state properties in photosynthetic purple bacterial reaction centers: effects of the protein environment. J Phys Chem B 115(21):7058-7068. doi:10.1021/jp200077e

Papiz MZ, Prince SM, Howard T, Cogdell RJ, Isaacs NW (2003) The structure and thermal motion of the B800-850 LH2 complex from Rps. acidophila at $2.0 \AA$ resolution and 100K: new structural features and functionally relevant motions. J Mol Biol 326(5):15231538. doi:10.1016/S0022-2836(03)00024-X

Ranck J, Ruiz T, Pehau-Arnaudet G, Arnoux B, Reiss-Husson F (2001) Two-dimensional structure of the native light-harvesting complex LH2 from Rubrivivax gelatinosus and of a truncated form. Biochim Biophys Acta 1506(1):67-78. doi:10.1016/ S0005-2728(01)00185-2

Rondonuwu FS, Taguchi T, Fujii R, Yokoyama K, Koyama Y, Watanabe $Y$ (2004) The energies and kinetics of triplet carotenoids in the LH2 antenna complexes as determined by phosphorescence spectroscopy. Chem Phys Lett 384(4-6):364-371. doi:10.1016/j. cplett.2003.12.024

Sipka G, Maróti P (2016) Induction and anisotropy of fluorescence of reaction center from photosynthetic bacterium Rhodobacter sphaeroides. Photosynth Res 127(1):61-68. doi:10.1007/ s11120-015-0096-y

Slouf V, Chabera P, Olsen JD, Martin EC, Qian P, Hunter CN, Polivka $\mathrm{T}$ (2012) Photoprotection in a purple phototrophic bacterium mediated by oxygen-dependent alteration of carotenoid excitedstate properties. Proc Natl Acad Sci USA 109(22):8570-8575. doi:10.1073/pnas.1201413109

Takaichi S (1999) Carotenoids and carotenogenesis in anoxygenic photosynthetic bacteria. In: Frank HA, Young AJ, Britton G, Cogdell 
RJ (eds) The photochemistry of carotenoids. Advances in photosynthesis and respiration, vol 8. Springer, Dordrecht, pp 39-69. doi:10.1007/0-306-48209-6_3

Ueda T, Morimoto Y, Sato M, Kakuno T, Yamashita J, Horio T (1985) Isolation, characterization, and comparison of a ubiquitous pigment-protein complex consisting of a reaction center and lightharvesting bacteriochlorophyll proteins present in purple photosynthetic bacteria. J Biochem 98(6):1487-1498. doi:10.1093/ oxfordjournals.jbchem.a135417

van Grondelle R, Duysens LN (1980) On the quenching of the fluorescence yield in photosynthetic systems. Plant Physiol 65(4):751754. doi:10.1104/pp.65.4.751

Vermeglio A, Nagashima S, Alric J, Arnoux P, Nagashima KV (2012) Photo-induced electron transfer in intact cells of
Rubrivivax gelatinosus mutants deleted in the RC-bound tetraheme cytochrome: insight into evolution of photosynthetic electron transport. Biochim Biophys Acta 1817(5):689-696. doi:10.1016/j.bbabio.2012.01.011

Wirtz AC, van Hemert MC, Lugtenburg J, Frank HA, Groenen EJ (2007) Two stereoisomers of spheroidene in the Rhodobacter sphaeroides R26 reaction center: a DFT analysis of resonance Raman spectra. Biophys J 93(3):981-991. doi:10.1529/ biophysj.106.103473

Wraight CA, Clayton RK (1974) The absolute quantum efficiency of bacteriochlorophyll photooxidation in reaction centres of Rhodopseudomonas spheroides. Biochim Biophys Acta 333(2):246-260. doi:10.1016/0005-2728(74)90009-7 